Elsevier required licence: (C) 2018

This manuscript version is made available under the CC-BY-NC-ND 4.0 license http://creativecommons.org/licenses/by-nc-nd/4.0/

The definitive publisher version is available online at

https://doi.org/10.1111/cwe.12246 


\title{
Are China's Exports Crowding Out or Being Crowded Out? Evidence from Japan's Imports
}

\author{
Yan Liu, Xunpeng Shi, James Laurenceson*
}

\begin{abstract}
Previous studies have investigated whether Chinese exports have crowded out those from other countries. However, what has yet to be considered is the evidence by different quality varieties. Using the most detailed Harmonized System nine-digit product-level data, the present paper provides evidence of crowding-out and crowdedout effects across different product quality segments and across manufacturing sectors by quality segments. The empirical evidence presented in this paper shows that the crowding-out effects of Chinese exports have been greatest at the lower end of the quality spectrum but less significant at the higher quality spectrum. Moreover, since 2007 China's own exports of lower quality manufactured goods have been increasingly crowded out. The key policy implication is that China's export path is in line with that taken by other Asian economies in previous decades; the crowded-out effect could achieve win-win outcomes for countries involved; and lower income countries would do well to be open to receive those relocated low value-added industries from China. However, the relocation policy in China is best implemented gradually as climbing up the product quality ladder takes time.
\end{abstract}

Keywords: constant market share analysis, crowded out, crowding out, industrial relocation

JEL codes: F14, N75, P33

\footnotetext{
*Yan Liu, Associate Professor, Department of International Economics and Trade, Dalian Minzu University, China. Email: lhyddhmt@163.com; Xunpeng Shi, Corresponding Author, Principal Research Fellow, Australia China Relations Institute, University of Technology Sydney, Australia. Email: xunpeng.shi@gmail.com; James Laurenceson, Professor and Deputy Director, Australia China Relations Institute, University of Technology Sydney, Australia. Email: James.Laurenceson@uts.edu.au. Yan Liu acknowledges financial support from the National Social Science Fund of China (No. 13CGJ034; Project Title "Research on the Chinese Manufacturing Export Quality”).
} 


\section{Introduction}

China's success in penetrating global markets has been widely documented(Du and Lu, 2018). In 2009, China became the world's largest exporting nation. By 2016, China's share of global goods exports had reached 13.6 percent, more than 4 percentage points higher than the USA in second place(World Trade Organization, 2017). This has given rise to a view that China's success has come at the expense of other countries and an extensive academic literature on the crowding-out effect of China's exports on its rivals has ensued(Holst and Weiss, 2004; Greenaway et al., 2008; Batista and Liu, 2017).

At the same time, however, a significant proportion of China's exports have come from foreign companies themselves, as they have relocated their production and assembly plants to take advantage of lower wage costs as well as other locational advantages such as high quality infrastructure. The latest data from China's customs administration show that foreign-funded enterprises currently account for 42.8 percent of China's total exports(CEIC, 2017).

Much of China's export success came during a period when China was classified as a low and lower-middle income country. Since 2010, wage increases have pushed China into the upper-middle income bracket of countries as defined by the World Bank. Manufacturing wages in China are now higher than in all South-East Asian countries apart from Singapore. At the same time, there is evidence that in some of China's major export destinations, such as Japan, China’s exports are themselves now being crowded out by competition from third countries (Figure 1). Just as China has historically benefited from high-income countries relocating their industrial facilities, there is 
evidence that Chinese firms are increasingly following suit by setting up in locations such as Vietnam, Bangladesh and Ethiopia. That is, there is anecdotal evidence that rather than China presenting a unique threat to the exports of other countries, it is proceeding along a familiar "flying geese" development path, outlined first by Akamatsu(1962).

Figure 1. Market Share of China in Japan’s Manufacturing Imports

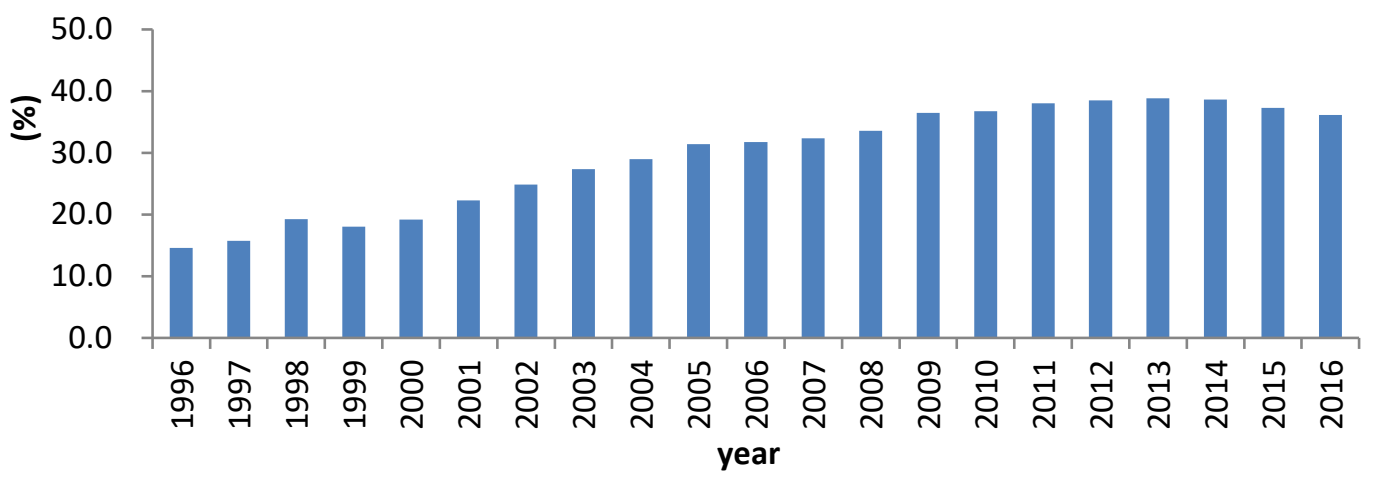

Source: Ministry of Finance, Japan.

This paper aims to provide a more nuanced assessment of China's export path and its implications. The major contribution is to consider changes in China's market share not at an aggregate level, but rather at the level of different product quality segments. For example, it may be that China has mostly made gains in market share with respect to low value-added products but has yet to displace those countries supplying at the higher end of the quality distribution. Alternatively, as wages in China have risen it may be that China's own exports of lower value-added products have been crowded out, and whether China has, in turn, been able to displace higher value-added products produced by other countries needs to be empirically determined.

To investigate this question, an improved constant market share (CMS) 
methodology is adopted to measure the crowding-out effect, which can result from both direct competition and also industrial relocation. The particular context considered in this paper is Japan's import market for manufactured goods. This is because China is a major supplier to this market, manufactured goods comprise a range of quality segments and also because Japanese import data are available at an extremely high level of product disaggregation, thus facilitating a detailed analysis of "crowding out” or being “crowded out” in different quality segments.

To the best of our knowledge, the present paper is the first to identify the shift from the crowding-out effect of China's exports to the crowded-out effects with respect to its ASEAN and East Asian neighbors.

The structure of this paper is as follows. Section II provides a brief overview of China's export performance in the Japanese market for imported manufactured goods. Section III details the methodology and data, followed by the presentation and discussion of results in Section IV. Section V summarizes the findings and highlights policy implications. Section VI concludes.

\section{The performance of China's Export and the Crowding-out Effect}

China's share in Japan's manufacturing imports grew enormously, from 14.6 percent in 1996 to 38.5 percent in 2012. It reached a maximum of 38.9 percent in 2013 and thereafter experienced a slight decline.

Table 1. Macro Market Share by Countries/Regions (\%)

$\begin{array}{llll}(1) & (2) \quad(3) \quad(4) \quad(5)\end{array}$




\begin{tabular}{|c|c|c|c|c|c|}
\hline & 1996 & 2002 & 2007 & 2012 & 2016 \\
\hline China & 14.6 & 24.8 & 32.3 & 38.5 & 36.1 \\
\hline ASEAN & 13.9 & 14.9 & 13.8 & 14.3 & 16.1 \\
\hline Singapore & 2.6 & 1.9 & 1.4 & 1.4 & 1.5 \\
\hline Malaysia & 3.6 & 3.5 & 2.6 & 2.4 & 2.3 \\
\hline Thailand & 3.2 & 3.6 & 3.9 & 3.9 & 3.9 \\
\hline Indonesia & 2.6 & 2.6 & 2.9 & 2.5 & 2.4 \\
\hline Philippines & 1.5 & 2.5 & 1.8 & 1.6 & 1.8 \\
\hline Vietnam & 0.4 & 0.8 & 1.1 & 2.1 & 3.6 \\
\hline Cambodia & 0.0 & 0.0 & 0.0 & 0.1 & 0.3 \\
\hline Myanmar & 0.0 & 0.0 & 0.1 & 0.1 & 0.2 \\
\hline Korea & 5.5 & 5.4 & 6.3 & 5.9 & 4.8 \\
\hline Taiwan, China & 5.2 & 5.5 & 4.7 & 4.5 & 5.0 \\
\hline Hong Kong, China & 1.0 & 0.5 & 0.3 & 0.1 & 0.1 \\
\hline Bangladesh & 0.0 & 0.0 & 0.1 & 0.3 & 0.6 \\
\hline India & 0.6 & 0.5 & 0.5 & 0.6 & 0.7 \\
\hline USA-Canada & 28.9 & 21.5 & 15.9 & 12.5 & 13.2 \\
\hline Western Europe & 21.8 & 19.7 & 17.4 & 16.9 & 17.4 \\
\hline Middle and South America & 2.1 & 1.8 & 2.2 & 2.0 & 2.0 \\
\hline Africa & 1.1 & 1.2 & 2.1 & 1.2 & 1.0 \\
\hline ROW & 5.3 & 4.2 & 4.4 & 3.2 & 3.0 \\
\hline Total & 100.0 & 100.0 & 100.0 & 100.0 & 100.0 \\
\hline
\end{tabular}

Source: Authors' own calculation.

In comparison with China, the change in share of ASEAN countries was small. Within ASEAN there were different patterns. As a high-income country, Singapore's share dropped from 2.6 percent in 1996 to 1.4 percent in 2007 and remained stable thereafter. Upper-middle income Malaysia dropped continuously, from 3.6 percent in 1996 to 2.3 percent in 2016. Thailand's share increased prior to 2007 and then remained stable. The share of the Philippines tended to fluctuate. Vietnam gained the most, with its share increasing from 0.4 percent in 1996 to 3.6 percent in 2016, thus making it the second largest exporter within ASEAN. The underdeveloped ASEAN members of Cambodia and Myanmar have only just begun to gain a small market share in recent periods, while Lao and Brunei are excluded from the analysis in this paper because they 
still possess an insignificant share.

Two of China’s major exporting neighbors, Korea and China's Taiwan, each accounts for around a 5-percent share.

The greatest decline was in the share of high-income USA-Canada, from 28.9 percent in 1996 to 12.5 percent in 2012, albeit with a minor recovery through to 2016. Western Europe's share also dropped considerably but the magnitude is less than USACanada's. This aligns with evidence reported by Fontagné et al.(2008) that Western Europe has been more resilient than the USA in facing rising exports from China.

Such dynamics in the Japanese market have occurred in other markets too. This has given rise to a literature studying the crowding-out effects of China's exports (AnhDao, 2010; Batista and Liu, 2017; Lin, 2015). Earlier studies with aggregate data often resulted in inconsistent findings. For example, Eichengreen et al. (2007) studied the impact of Chinese exports on 13 Asian exporting countries using aggregate trade data as well as SITC 1-digit and 3-digit data for 1990-2003. The main conclusions reached were that China's growth had a positive effect on exports of high-income (Japan, Singapore and Korea) and middle-income (Malaysia and the Philippines) countries but a negative effect on low-income Asian countries (Bangladesh, Cambodia, Sri Lanka and Pakistan). In contrast, also using aggregate data for 1990-2003, Greenaway et al. (2008)conclude that there is no evidence of export displacement for low-income countries(Bangladesh, Cambodia, India, Pakistan and Vietnam), which have a comparative advantage in unskilled labor-intensive goods and find, instead, that it was exports of high-income economies (Korea, Singapore and Japan) that were most 
adversely affected.

Such discrepancies have induced follow-up studies. For example, Eichengreen et al.(2007)finds that all else being equal, a 10-percent increase in Chinese exports to a particular market results in a 0.6-percent decline in the sales of competing Asian countries in that market. Similarly, Baak(2014)estimates the crowding-out effect of China's exports on Korea's exports using econometric methods and Japan's Harmonized System (HS)nine-digit-level import data. This indicates that if the Chinese unit price of a commodity decreases by 1 percent, the demand for Korean exports of the commodity decreases by 0.34 percent. Although these studies offer valuable quantitative estimates of the crowding-out effect, they do not address issues around quality heterogeneity of traded products.

Some previous studies have demonstrated that decomposing trade flows into quality segments makes it possible to more accurately measure the magnitude of the crowding-out effect. Scott (2004) argues that thinking about international specialization must shift away from industries and toward segments(with low, medium or high quality) within products to further investigate competition among exporters. Fontagné et al.(2008)concludes that the more detailed the product classification, the less competition among exporters. The present study shows that countries at different development levels sell quality-differentiated segments of the same products at very different prices and, thus, these countries do not compete directly because they are not positioned in the same market segment. A similar exercise was conducted between China and Vietnam(Anh-Dao, 2010).Such comparative studies show that a country's 
export growth in market value or market share in one quality segment of a given product does not mean it will crowd out the growth of other countries competing in another quality segment of the same product. By way of illustration, the export of a pair of US\$50 leather shoes with low quality is unlikely to crowd out the exports of a US\$300 pair of leather shoes of high quality. This means that it is necessary to consider product quality segmentation before estimating the crowding-out effect.

\section{Methodology and Data}

1. Quality Segmentation

Following Fontagné et al. (2008), each trade flow is divided into different quality segments. Classification proceeds as follows. The relative unit value ratio for any trade flow of product $i$ exported by country $j$ to a given importing market $k$ is denoted as: $r_{i j k}=u v_{i j k} / u v_{i k}$.The $u v_{i j k}$ is the unit value for the trade flow of product $I$ exported by country $j$ to a given importing market $k$ and $u v_{i k}$ is the trade-weighted (geometric) average of the unit value of product $i$ exported by all exporting countries in the given importing market, $k$.

If $r_{i j k}<1$ then the value of trade flow of product $I$ exported by country $j$ is divided into the low-quality and medium-quality segments.

If $r_{i j k}>1$ then the value of trade flow of product $i$ exported by country $j$ is divided into the medium-quality and high-quality segments.

If $r_{i j k}=1$ then the value of trade flow of product $I$ exported by country $j$ is ascribed to the medium-quality segments. See Equation (1): 


$$
\begin{cases}r_{i j k}<1 & \text { low quality share }:\left(1-r_{i j k}{ }^{\alpha}\right) ; \text { medium quality share }: r_{i j k}{ }^{\alpha} \\ r_{i j k}=1 & \text { medium quality share }: 100 \% \\ r_{i j k}>1 & \text { high quality share }: 1-1 / r_{i j k}^{\alpha} ; \text { medium quality share: } 1 / r_{i j k}{ }^{\alpha}\end{cases}
$$

Following Fontagné et al. (2008), we set the smoothness parameter $\alpha$ to be 4 so as to make each segment roughly equal to one-third of the world trade.

2. Decomposition and Distribution of the Crowding-out Effect

To measure the magnitude of the crowding-out effect, we employ the improved constant market shares (CMS) analysis method. The CMS has long been used in the research of export performance. The CMS model breaks down the change in the aggregated market share (or macro share)of a particular exporter into two main components: the direct competition effect, or the competitiveness effect, and the indirect competition effect, or the structural effect (Tyszynski, 1951; Fagerberg and Sollie, 1987; Holst and Weiss, 2004; Batista, 2008; Batista and Liu, 2017; Cheptea et al., 2014).

In this paper, we argue that the first component is a mixture of a competitiveness effect and an industry relocation effect because the micro market share gain in product level may be due to either direct competition against rivals or relocation of production facilities. Therefore, unlike previous literature, we refer to it as a crowding-out effect that reflects both factors. The following identity shows the CMS decomposition: 


$$
\Delta M_{j k}^{t+1, t} \equiv \underbrace{\left(\mathbf{a}_{i j k}^{t+1}-\mathbf{a}_{i j k}^{t}\right) \mathbf{b}_{i k}^{t}}_{\text {Crowding-out effect, } \left.\mathrm{COE}_{j k}\right)}+\underbrace{\mathbf{a}_{i j k}^{t+1}\left(\mathbf{b}_{i k}^{t+1}-\mathbf{b}_{i k}^{t}\right)}_{\text {(structual effect, } \left.\mathrm{SLE}_{j k}\right)}
$$

where $\Delta M_{j k}^{t+1, t}$ is the aggregated macro market share change of country $j$ in the importing country $k$ from the initial year $t$ to the final year $t+1$. $\mathbf{a}_{i j k}^{t} \equiv\left(X_{1 j k}^{t} / M_{1 k}^{t}, \ldots X_{i j k}^{t} / M_{i k}^{t} \ldots, X_{n j k}^{t} / M_{n k}^{t}\right)$ is a row vector of dimension $n$ of the micro shares of product $i(i=1, \ldots n)$ exported by country $j$ to a given importing market $k$ in initial year t. $X_{i j k}^{t}$ is the market value of trade flow of product $I$ exported by country $j$ to a given importing market kin initial year $t . M_{i k}^{t}$ is the market value of all trade flows of product $I$ imported by a given importing market $k$ in initial year $t . \mathbf{b}_{i k}^{t} \equiv\left(M_{1 k}^{t} / M_{k}^{t}, \ldots M_{i k}^{t} / M_{k}^{t} \ldots, M_{n k}^{t} / M_{k}^{t}\right)$ is a column vector of dimension $n$ of the shares of product $I(i=1, \ldots n)$ in the total imports of country $j$ in initial year $t$.

The alternative form of CMS decomposition is as follows:

$$
\Delta M_{j k}^{t+1, t} \equiv \underbrace{\left(\mathbf{a}_{i j k}^{t+1}-\mathbf{a}_{i j k}^{t}\right) \mathbf{b}_{i k}^{t+1}}_{\text {(Crowding-out effect, } \left.\mathrm{COE}_{j k}^{t+1, t}\right)}+\underbrace{\mathbf{a}_{i j k}^{t}\left(\mathbf{b}_{i k}^{t+1}\right)}_{\text {(structual effect, } \mathrm{SLE}}
$$

As pointed out by Fagerberg and Sollie (1987), the CMS method can be considerably improved in terms of theoretical consistency as well as empirical applicability if initial years' weights ( $\mathbf{b}_{i k}^{t}$, Laspeyres indices) are used throughout the calculations. Thus, we use the Laspeyres indices CMS model as shown in Equation (2)

\footnotetext{
${ }^{1}$ For dead products, which are imported in the initial year and not imported in the final year by Japan, COE is meaningless because there is no import demand and, consequently, no competition between rivals. However, according to the formula, COE for dead products is negative. Therefore, we exclude dead products in the following tables of CMS results.
} 
to measure the crowding-out effect of China's exports on other countries.

Following Batista (2008), we further distribute the crowding-out effect of country $j$ across its rivals as follows:

$$
\Delta M_{j, s}^{t+1, t}=\mathbf{a}_{i s k}^{t} \mathrm{COE}_{i j k}^{t+1, t}-\mathbf{a}_{i j k}^{t} \mathrm{COE}_{i s k}^{t+1, t}
$$

where $\Delta M_{j, s}^{t+1, t}$ is the part of the change in its macro market share of country $j$ from initial year tto the final year $t+1$ that can be ascribed to crowding out the export of country s. $\mathbf{a}_{i s k}^{t} \equiv\left(X_{1 s k}^{t} / M_{1 k}^{t}, \ldots X_{i s k}^{t} / M_{i k}^{t} \ldots, X_{n s k}^{t} / M_{n k}^{t}\right)$ is a row vector of dimension $n$ of the micro shares of product $i(i=1, \ldots n)$ exported by country $s$ to a given importing market $k$ in initial year $t$ and $\mathbf{a}_{\text {isk }}^{t}$ is introduced as above. $\mathrm{COE}_{i j k}^{t+1, t} \equiv\left(\mathrm{COE}_{1 j k}^{t+1, t}, \ldots C O E_{i j k}^{t+1, t}, \ldots C O E_{n j k}^{t+1, t}\right)$ is a column vector of dimension $n$ of the crowding-out effect in each individual product $i(i=1, \ldots n))$ exported by country $j$ to a given importing market $k$ from the initial year $t$ to the final year $t+1$; $\mathrm{COE}_{i s k}^{t+1, t} \equiv\left(\mathrm{COE}_{1 s k}^{t+1, t}, \ldots C O E_{i s k}^{t+1, t}, \ldots C O E_{n s k}^{t+1, t}\right)$ is a column vector of dimension $n$ of the crowding-out effect in each individual product $i(i=1, \ldots n)$ exported by country $s$ to a given importing market $k$ from the initial year $t$ to the final year $t+1$;

\section{Data}

With the purpose of minimizing aggregation bias(Batista and Liu, 2017), this paper uses HS nine-digit Japanese import C.I.F. data, which is the most detailed data available. The annual data is from Japan's Ministry of Finance (MOF). We define a HS nine-digit code as a product. A segment within a product refers to the low, medium or high-quality 
segments within that product. This paper only considers products from chapter 28 to 96 (manufactured products) for which information on values and quantities is available, thus allowing the calculation of unit values.

The HS was introduced in 1988 and revised in1992, 1996, 2002, 2007 and 2012. To trace each product category consistently through time, we use the initial and endyear data of our sub-periods: 1996-2001, 2002-2006, 2007-2011 and 2012-2016.An additional benefit of using the above sub-periods is as follows: China joined the World Trade Organization (WTO) at the end of 2001 and comparisons between the first and subsequent sub-periods might show the crowding-out effect this had on China's competitors. According to the World Bank, China became an upper-middle income country in 2010 and, thus, we can use the third sub-period to examine the impact of rising labor costs on the crowding-out effect. We would expect to see a negative impact, which might even be sufficient to tip a crowding-out effect to a crowded-out effect. Finally, as mentioned in Section II, China's macro market share began to decline gradually on a year-on-year basis after 2013. Thus, the latest sub-period can be used to observe whether there has been a possible widening of the crowded-out effect.

\section{Results}

1. Export Performance by Quality Segment

\section{(1) Market Share in Low Segment}

Table 2 shows that in the low-quality segment of China's market share rose continuously before 2012 but fell thereafter. The fall in the last sub-period was 
sufficient to return China's market share to less than it was in 2007. It is notable that China's market share in low-quality products is considerably higher than its macro market share shown in Table 1.

Since China entered the WTO, ASEAN countries as a whole began to lose market share in the low-quality segment. Note that compared with the drop in ASEAN market share shown in Table 1, the drop in the low-quality segment in Table 2 is more dramatic. This shows the importance of considering product segmentation along a quality ladder. That said, in the most recent sub-period its share rose from 13.7 to 16.5 percent.

Within ASEAN, with the exception of Vietnam and Singapore, most member countries follow a rise-fall-rise pattern in their market shares. For instance, Thailand's share rose from 4.4 percent in 1996 to 5.2 percent in 2002, then fell to 4.4 percent in 2012 and finally rose to 4.8 percent in 2016. Meanwhile, Vietnam's share rose continuously even in the years when ASEAN as a whole lost market share. By 2016, Vietnam followed only Thailand as an exporter in the low-quality segment. Singapore's share experienced continuous decline. Singapore's fall and Vietnam's rise in the lowquality segment appears consistent with the expected industrial relocation under the flying geese model.

As important high-income trading partners of Japan, Korea’s share fluctuates more often, while China Taiwan’s share decreases continuously.

The high-income USA-Canada's share dropped significantly between 1996 and 2002, which is consistent with the theoretical expectation of industrial relocation. The 
high-income Western European countries only experienced modest declines in shares before 2012 and have gained slightly since then.

Table 2.Market Share by Countries/regions in Low Segment (\%)

\begin{tabular}{lccccc}
\hline Country/region & 1996 & 2002 & 2007 & 2012 & 2016 \\
China & 30.1 & 43.3 & 51.4 & 52.6 & 47.4 \\
ASEAN & 17.5 & 17.7 & 13.8 & 13.7 & 16.5 \\
$\quad$ Singapore & 4.4 & 1.8 & 1.2 & 0.9 & 1.3 \\
$\quad$ Malaysia & 4.2 & 4.9 & 2.5 & 2.5 & 2.6 \\
$\quad$ Thailand & 4.4 & 5.2 & 4.6 & 4.4 & 4.8 \\
$\quad$ Indonesia & 2.1 & 2.4 & 2.2 & 2.1 & 2.1 \\
$\quad 1.9$ & 2.6 & 2.0 & 1.4 & 1.5 \\
$\quad$ Philippines & 0.6 & 0.7 & 1.2 & 2.0 & 3.4 \\
$\quad$ Vietnam & 0.0 & 0.0 & 0.0 & 0.1 & 0.4 \\
$\quad$ Cambodia & 0.0 & 0.0 & 0.1 & 0.2 & 0.4 \\
$\quad$ Myanmar & 5.6 & 6.3 & 4.8 & 5.3 & 5.7 \\
Korea & 9.7 & 6.6 & 6.5 & 5.5 & 5.5 \\
Taiwan, China & 1.3 & 0.9 & 0.3 & 0.2 & 0.2 \\
Hong Kong, China & 0.0 & 0.0 & 0.1 & 0.3 & 0.6 \\
Bangladesh & 1.5 & 0.9 & 0.8 & 1.0 & 1.2 \\
India & 18.2 & 8.8 & 8.4 & 8.5 & 7.8 \\
USA - Canada & 11.5 & 11.6 & 10.3 & 10.1 & 11.4 \\
Western Europe & 1.0 & 1.2 & 1.0 & 1.0 & 1.7 \\
Middle and South America & 0.4 & 0.2 & 0.8 & 0.3 & 0.4 \\
Africa & 3.2 & 2.5 & 1.8 & 1.5 & 1.6 \\
ROW & 100.0 & 100.0 & 100.0 & 100.0 & 100.0 \\
\hline Total & & & & &
\end{tabular}

Source: Authors’ own calculation

\section{(2) Market Share in Medium Segment}

Turning to Table 3, in the medium segment China continuously gained market share before 2012. After that, from 2012 to 2016, China's share steadied. This may indicate that China's comparative advantage currently rests with medium-quality products.

Relative to China's continuous gain of market share before 2012, ASEAN countries, as a whole, experienced a relatively stable share throughout the full period. 
Table 3.Market Share by Countries/regions in Medium Segment (\%)

\begin{tabular}{lccccc}
\hline Country/region & 1996 & 2002 & 2007 & 2012 & 2016 \\
\hline China & 12.4 & 25.9 & 34.7 & 45.3 & 45.1 \\
ASEAN & 15.2 & 15.0 & 14.2 & 14.0 & 15.3 \\
$\quad$ Singapore & 2.1 & 1.5 & 0.8 & 0.9 & 1.2 \\
$\quad$ Malaysia & 4.6 & 3.5 & 2.5 & 2.2 & 1.9 \\
$\quad$ Thailand & 3.2 & 3.4 & 3.8 & 4.0 & 3.5 \\
$\quad$ Indonesia & 3.7 & 3.7 & 4.4 & 3.5 & 3.0 \\
$\quad$ Philippines & 1.3 & 2.0 & 1.5 & 1.2 & 1.7 \\
$\quad$ Vietnam & 0.4 & 0.8 & 1.1 & 2.1 & 3.6 \\
$\quad$ Cambodia & 0.0 & 0.1 & 0.1 & 0.1 & 0.3 \\
$\quad$ Myanmar & 0.0 & 0.0 & 0.0 & 0.1 & 0.2 \\
Korea & 5.2 & 5.5 & 5.3 & 6.9 & 4.8 \\
Taiwan, China & 4.3 & 5.0 & 4.0 & 3.5 & 3.8 \\
Hong Kong, China & 0.6 & 0.3 & 0.2 & 0.1 & 0.1 \\
Bangladesh & 0.0 & 0.0 & 0.0 & 0.1 & 0.2 \\
India & 0.3 & 0.3 & 0.4 & 0.4 & 0.4 \\
USA - Canada & 33.5 & 23.4 & 16.4 & 9.9 & 11.5 \\
Western Europe & 15.9 & 14.2 & 11.5 & 11.2 & 11.2 \\
Middle and South America & 3.0 & 1.7 & 2.5 & 2.3 & 2.1 \\
Africa & 2.1 & 2.4 & 3.9 & 2.1 & 1.9 \\
ROW & 7.5 & 6.3 & 6.9 & 4.2 & 3.6 \\
\hline Total & 100.0 & 100.0 & 100.0 & 100.0 & 100.0 \\
\hline
\end{tabular}

Source: Authors' own calculation.

Among ASEAN countries, Singapore's share fell and then rose. Malaysia lost market share continuously. Both Thailand and Indonesia gained market share first and then subsequently lost it, while the share of the Philippines moved irregularly. Vietnam also stands out in the medium-quality segment. Its share rose from just 0.4 percent in 1996 to 3.6percent in 2016. It is now the largest ASEAN exporter to the Japanese market in the medium-quality segment. Both Cambodia and Myanmar experienced a rise in share between 2012 and 2016. Although the increase is minor in size, it is a significant advance for both countries. Myanmar doubled its share in 2016 relative to 2012, while Cambodia tripled its share during the same sub-period. 
Korea's share and China Taiwan's share are still bigger than that of any individual ASEAN economy. Both economies' shares move irregularly. Different from in the lowquality segment, the developed USA-Canada lost the biggest market share in the medium-quality segment, falling from 33.5 percent in 1996 to 9.9 percent in 2012. USA-Canada then registered a small recovery to 11.2 percent in 2016. Western Europe’s share also fell but the magnitude is small relative to USA-Canada.

\section{(3) Market Share in High Segment}

Although China has been the largest exporter in low and medium segments in Japan's market, its share of the high segment is vastly lower. It accounted for only 1.2 percent of Japan's high-quality market in 1996, less than the shares of some ASEAN countries such as Singapore (1.6 percent), Malaysia (1.4 percent), Thailand (1.9 percent)and the Philippines (1.5 percent). By 2016, China accounted for 5.4 percent, which saw it ranked fourth in the high-quality segment. Nonetheless, China still experienced a market share loss in the period 2012-2016 that was almost as large as the market share gain of ASEAN.

ASEAN's share of the high-quality segment increased continuously over the entire period. In particular, Vietnam has become the largest ASEAN exporter in this segment. Singapore doubled its share between 1996 and 2012 but then fell again in the most recent sub-period. Malaysia's share rose significantly during the first two sub-periods and then steadied. Thailand's share rose continuously and it has become the second largest ASEAN exporter in the high-quality segment following Vietnam. Indonesia's 
share was small and stable before 2012, and after that, it increased. The Philippines doubled its share between 1996 and 2002 and then moved irregularly. Not surprisingly, the underdeveloped members of Cambodia and Myanmar did not gain market share in the high-quality segment.

Both Korea and China Taiwan's shares moved irregularly. Although the share of high-income countries decreased between 1996 and 2016, they are still the largest source of Japanese high-quality imports. For USA-Canada, the largest drop in its share took place between 2002 and 2007. This was the period that Korea gained its largest share. For Western Europe, the largest drop in its share took place between 1996 and 2002,when China’s Taiwan gained its largest market share.

Table 4.Market Share by Countries/Regions in High-quality Segment (\%)

\begin{tabular}{lccccc}
\hline Country/region & 1996 & 2002 & 2007 & 2012 & 2016 \\
\hline China & 1.2 & 2.6 & 3.8 & 6.6 & 5.4 \\
ASEAN & 7.9 & 11.5 & 13.1 & 15.6 & 16.9 \\
$\quad$ Singapore & 1.6 & 2.3 & 2.6 & 3.2 & 2.3 \\
$\quad$ Malaysia & 1.4 & 2.0 & 2.9 & 2.8 & 2.8 \\
$\quad$ Thailand & 1.9 & 2.0 & 3.2 & 3.3 & 3.4 \\
$\quad$ Indonesia & 1.2 & 1.1 & 1.1 & 1.3 & 1.9 \\
$\quad$ Philippines & 1.5 & 3.3 & 2.2 & 2.6 & 2.3 \\
$\quad$ Vietnam & 0.3 & 0.7 & 1.1 & 2.3 & 3.9 \\
$\quad$ Cambodia & 0.0 & 0.0 & 0.0 & 0.0 & 0.1 \\
$\quad$ Myanmar & 0.0 & 0.0 & 0.0 & 0.0 & 0.1 \\
Korea & 5.9 & 4.4 & 9.9 & 4.7 & 3.8 \\
Taiwan, China & 1.7 & 5.2 & 3.8 & 5.2 & 6.6 \\
Hong Kong, China & 1.3 & 0.5 & 0.4 & 0.3 & 0.2 \\
Bangladesh & 0.0 & 0.0 & 0.1 & 0.1 & 0.1 \\
India & 0.2 & 0.2 & 0.4 & 0.4 & 0.6 \\
& & & & & \\
USA-Canada & 33.2 & 32.8 & 24.7 & 23.0 & 23.4 \\
Western Europe & 42.7 & 36.6 & 36.8 & 36.9 & 36.4 \\
Middle and South America & 1.8 & 2.7 & 3.0 & 2.8 & 2.4 \\
Africa & 0.3 & 0.8 & 0.3 & 0.4 & 0.3 \\
ROW & 3.8 & 2.7 & 3.7 & 4.0 & 3.9 \\
\hline
\end{tabular}




\begin{tabular}{lrrrrr}
\hline Total & 100.0 & 100.0 & 100.0 & 100.0 & 100.0 \\
\hline
\end{tabular}

Source: Authors' own calculation.

These results suggest that crowding-out effects may exist between any two exporting economies. However, changes in market share itself cannot be used to measure the crowding-out effect. Therefore, we utilize the CMS model and its extension, as shown in Equations (2) and (4),to decompose the market share change and then analyze the distribution of China's crowding-out or crowded-out effect among rivals.

2. The Relative Change of China's Market Share to Its Competitors: Crowdingout or Crowded-out Effect

\section{(1) Low-quality Segment}

According to Table 2, China's market share in the low segment rose from 30.1 percent in 1996 to 47.4 percent in 2016. Column (1) of Table 5showsthat the overall crowding-out effect of China was 14 percent more market share in the low-quality segment. Recall that this crowding out can reflect either direct competition or industrial relocation. Thus, the crowding-out effect accounts for 80.9 percent (14.0/17.3) of China's market share change in the low segment. The remaining 19.1 percent can be attributed to the non-competitive structural effect. The high proportion of crowding out is indicative of China's competitive advantage in the low-quality segment, as predicted by trade theory. With respect to the14-percentcrowding-out effect, 5.2 percent is from China’s Taiwan, 2.6 percent from Western Europe, 1.9 percent from Korea, 1.8 percent from ASEAN and 1.8 percent from USA-Canada. On the flipside, China was also crowded out by low-income countries such as Vietnam ( -1.7 percent), Cambodia ( -0.4 
percent), Myanmar ( -0.3 percent) and Bangladesh ( -0.5 percent). This is consistent with the shift of manufacturing capacity from earlier developed Asian countries to China, and subsequent moves to less developed Asian countries, a typical pattern of industry relocation.

Table 5. The Distribution of China’s Crowding-out Effect in Low Segment (\%)

\begin{tabular}{|c|c|c|c|c|c|}
\hline Country/Region & $\begin{array}{c}(1) \\
1996- \\
2016\end{array}$ & $\begin{array}{r}(2) \\
1996- \\
2001\end{array}$ & $\begin{array}{c}(3) \\
2002- \\
2006\end{array}$ & $\begin{array}{r}\quad(4) \\
2007- \\
2011\end{array}$ & $\begin{array}{c}\quad(5) \\
2012- \\
2016\end{array}$ \\
\hline ASEAN & 1.80 & 1.70 & 3.30 & -0.70 & -2.50 \\
\hline Singapore & 1.4 & 0.7 & 0.6 & 0.1 & 0.1 \\
\hline Malaysia & 1.3 & 0.3 & 1.3 & -0.1 & -0.2 \\
\hline Thailand & 0.6 & 0.5 & 0.7 & 0.0 & -0.6 \\
\hline Indonesia & 0.4 & 0.2 & 0.4 & 0.0 & -0.2 \\
\hline Philippines & 0.5 & 0.1 & 0.5 & -0.1 & -0.1 \\
\hline Vietnam & -1.7 & -0.1 & -0.2 & -0.4 & -1.0 \\
\hline Cambodia & -0.4 & 0.0 & 0.0 & -0.1 & -0.3 \\
\hline Myanmar & -0.3 & 0.0 & 0.0 & -0.1 & -0.2 \\
\hline Korea & 1.9 & 0.9 & 1.5 & 0.2 & -0.7 \\
\hline Taiwan, China & 5.2 & 2.3 & 1.9 & 1.2 & -0.3 \\
\hline Hong Kong, China & 0.7 & 0.4 & 0.3 & 0.1 & 0.0 \\
\hline Bangladesh & -0.5 & 0.0 & 0.0 & -0.2 & -0.3 \\
\hline India & -0.2 & 0.1 & 0.0 & -0.1 & -0.1 \\
\hline USA-Canada & 1.8 & 1.0 & 0.5 & 0.0 & 0.3 \\
\hline Western Europe & 2.6 & 0.8 & 1.2 & 0.4 & 0.2 \\
\hline $\begin{array}{l}\text { Middle and South } \\
\text { America }\end{array}$ & 0.1 & 0.1 & 0.2 & 0.0 & -0.1 \\
\hline Africa & 0.0 & 0.0 & 0.0 & 0.0 & 0.0 \\
\hline ROW & 0.6 & 0.2 & 0.4 & 0.1 & 0.0 \\
\hline Total & 14.0 & 7.3 & 9.1 & 1.0 & -3.4 \\
\hline
\end{tabular}

Source: Authors’ own calculation.

When we break up the period into four sub-periods, a more detailed picture emerges. First, in the first two sub-periods in columns (2) and (3), apart from Vietnam, China crowds out all other exporting economies, especially its East Asian and ASEAN 
neighbors, which confirms the crowding-out effect identified in the previous literature. Second, by the third sub-period in column (4),however, while China still crowds out high-income countries, it, in turn, began to be crowded out by most developing ASEAN countries, especially Vietnam and Bangladesh. Crowded-out effects emerge extensively for the first time for China in the low-quality segment. In the latest sub-period in column (5), the crowded-out effect has increased. China lost market share to all its neighboring East Asian and ASEAN member countries, except high income Singapore and USACanada and Western European countries. Vietnam gained the largest share in the crowding out of China.

\section{(2) Medium-quality Segment}

As shown in column (1) of Table 6, in the medium-quality segment China gained 8.9 percent through crowding out rivals. According to Table 3, China's market share in this segment rose from 12.4 percent in 1996 to 45.1 percent in 2016. Thus, the crowding-out effect only accounts for 27.2 percent(8.9/32.6) of China's total market share increase in the medium-quality segment, a much lower proportion than in the lowquality segment.

Table 6. Distribution of China’s Crowding-out Effect in Medium Segment (\%)

\begin{tabular}{|c|c|c|c|c|c|}
\hline & (1) & (2) & (3) & (4) & (5) \\
\hline Country/region & $\begin{array}{l}1996- \\
2016\end{array}$ & $\begin{array}{l}1996- \\
2001\end{array}$ & $\begin{array}{l}2002- \\
2006\end{array}$ & $\begin{array}{l}2007- \\
2011\end{array}$ & $\begin{array}{l}2012- \\
2016\end{array}$ \\
\hline ASEAN & 1.60 & 1.80 & 1.40 & 0.30 & -2.20 \\
\hline Singapore & 0.6 & 0.3 & 0.1 & 0.0 & 0.0 \\
\hline Malaysia & 0.9 & 0.3 & 0.5 & 0.2 & -0.1 \\
\hline Thailand & 0.8 & 0.4 & 0.1 & 0.3 & -0.1 \\
\hline Indonesia & 0.4 & 0.3 & 0.3 & -0.1 & -0.2 \\
\hline Philippines & 1.0 & 0.5 & 0.4 & 0.2 & -0.1 \\
\hline
\end{tabular}




\begin{tabular}{lrrrrr}
\hline \multicolumn{1}{c}{ Vietnam } & -1.6 & 0.1 & 0.0 & -0.3 & -1.4 \\
\multicolumn{1}{c}{ Cambodia } & -0.3 & -0.1 & 0.0 & 0.0 & -0.2 \\
Korea & -0.2 & 0.0 & 0.0 & 0.0 & -0.1 \\
Taiwan, China & 3.2 & 0.8 & 0.9 & 0.3 & 1.3 \\
Hong Kong, China & 2.0 & 0.3 & 1.5 & 0.2 & -0.1 \\
Bangladesh & 0.2 & 0.1 & 0.0 & 0.0 & 0.0 \\
India & -0.1 & 0.0 & 0.0 & 0.0 & -0.1 \\
USA-Canada & -0.1 & 0.0 & 0.0 & -0.1 & 0.0 \\
Western Europe & 2.0 & 0.8 & 0.8 & 0.3 & 0.1 \\
Middle and South & -0.8 & -1.4 & 0.5 & 0.2 & -0.1 \\
America & 0.0 & -0.1 & 0.0 & 0.0 & 0.0 \\
Africa & 0.0 & 0.0 & 0.0 & 0.0 & 0.0 \\
ROW & 0.8 & 0.6 & 0.2 & 0.1 & -0.1 \\
\hline Total & 8.9 & 3.0 & 5.5 & 1.4 & -1.1 \\
\hline
\end{tabular}

Source: Authors' own calculation.

In the early sub-periods in columns (2) and (3), China's exports in the mediumquality segment crowded out most other competitors, with the exception of Western Europe, Cambodia and Middle and South America. For the third sub-period in column (4), although the effect decreased to 1.4 percent, crowding out still occurred for most exporters, except Indonesia, Vietnam and India. The situation changed in the last subperiod (column 5), during which China was crowded out by ASEAN and some East Asian neighbors. The exception is Korea and USA-Canada. China still gained 1.3 percent and 0.1 percent market shares from them, respectively. Like the low-quality segment, Vietnam also made the largest gains in crowding out China. For the last two sub-periods, China lost 0.3 and 1.4 percent in market share to Vietnam.

According to Table 3, China's share declined from 45.3 percent in 2012 to 45.1 percent in 2016.For the latest sub-period in column (5) in Table 6, China lost 1.1 percent market share in total. A relatively larger crowded-out effect is offset by the relatively 
larger structural effect, which, in turn, stabilized the magnitude of market share losses.

\section{(3) High-quality Segment}

In the high-quality segment, according to Table 4, China's market share rose from 1.2 percent in 1996 to 5.4 percent in 2016. However, as shown in column (1) in Table 7, China only gained 0.2 percent more market share between 1996 and 2016 in the highquality segment due to the crowding-out effect. This implies that the crowding-out effect only accounts for 4.8 percent(0.2/4.2) of China's total market share increase in the high-quality segment, with the remaining market share gains coming from the noncompetitive structural effect. The low overall crowding-out effect displays the fact that China's competitiveness is still modest in high-quality products relative to developed countries.

In the first sub-period in column (2), we cannot observe a crowding-out effect of China's exports on other ASEAN and East Asian countries. In the same sub-period, we can only observe a 0.2-percent crowding-out effect of China on high-income USACanada and Western Europe.

For the second sub-period in column (3), we can observe the crowding-out effect of China on some upper-middle and high-income ASEAN and East Asian economies, including Singapore, Thailand, Korea and China’s Taiwan. In addition, China still gains small market shares of 0.2 and 0.1 percent in crowding out high income USA-Canada and Western Europe countries, respectively. This is also true in the third sub-period in column (4). 
In the latest sub-period in column (5), the market share of 1.2 percent by its rivals crowded out China. In this sub-period, we can observe for the first time the aggregate shift from the previous crowding-out effect to a crowded-out effect. China was crowded out by some ASEAN and East Asian economies, including Singapore ( -0.2 percent), Malaysia ( -0.1 percent), Thailand ( -0.3 percent), Vietnam ( -0.2 percent) and Korea ( -0.1 percent). In addition, China was also crowded out by high income USA-Canada (-0.2 percent) and Western Europe countries (-0.1percent).

Table 7. Distribution of China’s Crowding-out Effect in High Segment (\%)

\begin{tabular}{|c|c|c|c|c|c|}
\hline \multirow{2}{*}{ Country/region } & (1) & $(2)$ & (3) & (4) & (5) \\
\hline & 1996-16 & $1996-01$ & 2002-06 & 2007-11 & 2012-16 \\
\hline ASEAN & -0.30 & 0.00 & 0.20 & 0.30 & -0.60 \\
\hline Singapore & -0.1 & 0.0 & 0.1 & 0.0 & -0.2 \\
\hline Malaysia & -0.1 & 0.0 & 0.0 & 0.1 & -0.1 \\
\hline Thailand & 0.1 & 0.0 & 0.1 & 0.2 & -0.3 \\
\hline Indonesia & 0.0 & 0.0 & 0.0 & 0.0 & 0.0 \\
\hline Philippines & 0.1 & 0.0 & 0.0 & 0.0 & 0.2 \\
\hline Vietnam & -0.3 & 0.0 & 0.0 & 0.0 & -0.2 \\
\hline Cambodia & 0.0 & 0.0 & 0.0 & 0.0 & 0.0 \\
\hline Myanmar & 0.0 & 0.0 & 0.0 & 0.0 & 0.0 \\
\hline Korea, Rep. & 0.1 & 0.0 & 0.1 & 0.1 & -0.1 \\
\hline Taiwan, China & 0.1 & 0.0 & 0.1 & 0.0 & 0.0 \\
\hline Hong Kong, China & 0.1 & 0.0 & 0.0 & 0.0 & 0.0 \\
\hline Bangladesh & 0.0 & 0.0 & 0.0 & 0.0 & 0.0 \\
\hline India & 0.0 & 0.0 & 0.0 & 0.0 & 0.0 \\
\hline USA-Canada & 0.1 & 0.1 & 0.2 & 0.1 & -0.2 \\
\hline Western Europe & 0.3 & 0.1 & 0.1 & 0.1 & -0.1 \\
\hline Middle and South America & 0.0 & 0.0 & 0.0 & 0.0 & 0.0 \\
\hline Africa & 0.0 & 0.0 & 0.0 & -0.1 & 0.0 \\
\hline ROW & -0.1 & 0.0 & 0.0 & 0.0 & -0.1 \\
\hline total & 0.2 & 0.2 & 0.7 & 0.6 & -1.2 \\
\hline
\end{tabular}

Source: Authors’ own calculation.

3. Further Analysis by Industries

The CMS analysis in Subsection IV.2 provided evidence of the crowding-out effect and, more recently, the crowded-out effect of China's exports upon rivals with varying 
degrees of magnitude depending on the quality segment being discussed. In this subsection, we undertake a supplementary analysis of China's crowding (crowded)-out effect across manufacturing sectors by quality segments.

\section{(1) Low-quality Segment}

According to column (1) in Table 8, the largest part of China's overall crowdingout effect of 14 percent in the low-quality segment between 1996 and 2016 comes from the sector of machines and electronics (8.5 percent). This is followed by miscellaneous (2.3 percent), chemicals (1.3 percent) and metals (1.0 percent). The textile and clothing sector ( -0.8 percent) and hides and skins sector ( -0.2 percent) have been crowded out by rivals during the past two decades.

After breaking up the full period into sub-periods, the dynamics of the crowdingout effect are more evident. For the first two sub-periods, as shown in columns (2) and (3), China crowded out rivals in all manufacturing sectors. The machines and electronics sector gained the largest market share. In contrast, in the third sub-period, as shown in column (4), as its labor costs rose China began to be crowded out in textiles and clothing ( -0.7 percent) and wood ( -0.1 percent). During this sub-period China still achieved a crowding-out effect (0.9 percent) in machines and electronics but the size was much diminished compared with previous sub-periods. In the latest sub-period however, China was crowded out by as much as a 2.3-percentmarket share in machines and electronics, followed by the textile and clothing sector ( -0.9 percent) and the hides and skins sector ( -0.3 percent). For the other sectors, there are positive crowding-out effects, but their size is small. 
Table 8. Distribution of China's Crowding-out Effect in Low Segment

\begin{tabular}{lccccc}
\hline Manufacturing sector & $(1)$ & $(2)$ & $(3)$ & $(4)$ & $(5)$ \\
& $1996-$ & $1996-$ & $2002-$ & $2007-$ & $2012-$ \\
& 2016 & 2001 & 2006 & 2011 & 2016 \\
\hline Chemicals(28-38) & 1.3 & 0.5 & 0.5 & 0.2 & 0.2 \\
Plastic or rubber(39-40) & 0.6 & 0.2 & 0.4 & 0.1 & 0.0 \\
Hides and skins (41-43) & -0.2 & 0.1 & 0.0 & 0.0 & -0.3 \\
Wood (44-49) & 0.1 & 0.1 & 0.1 & -0.1 & 0.0 \\
Textiles and clothing(50- & -0.8 & 0.8 & 0.0 & -0.7 & -0.9 \\
63) & 0.0 & 0.0 & 0.0 & 0.0 & 0.0 \\
Footwear(64-67) & 0.5 & 0.2 & 0.2 & 0.1 & 0.0 \\
Stone and glass(68-71) & 1.0 & 0.3 & 0.6 & 0.2 & 0.0 \\
Metals (72-73) & $8.5 \%$ & 3.4 & 6.5 & 0.9 & -2.3 \\
Machines and & & & & & \\
electronics(84-85) & 0.5 & 0.1 & 0.2 & 0.1 & 0.0 \\
Transport equipment(86- & & 1.5 & 0.6 & 0.2 & 0.1 \\
89) & 2.3 & 7.3 & 9.1 & 1.0 & -3.4 \\
Miscellaneous(90-96) & 14.0 & & &
\end{tabular}

Source: Authors’ own calculation.

\section{(2) Medium-quality Segment}

In the medium-quality segment, as shown in column (1) in Table 9, the sector most responsible for China's overall crowding-out effect of 8.9 percent between 1996 and 2016 was machines and electronics (6.9 percent). This is followed by sectors of chemicals ( 0.8 percent), metals ( 0.6 percent) and transportation equipment ( 0.5 percent). Textiles and clothing ( -1.3 percent), stone and glass ( -0.3 percent) and footwear $(-0.1$ percent) are sectors that have been crowded out by rivals during the past two decades.

New details emerge when we examine the results in sub-periods. For the first two sub-periods, as shown in columns (2) and (3), China crowds out rivals in most sectors, with the exceptions of textiles and clothing and stone and glass in the first sub-period. China's largest crowding-out effect is in machines and electronics (2.0 and 3.1 percent, 
respectively). For the last two sub-periods, China began to be increasingly crowded out in textiles and clothing from -0.3 percent in the third sub-period to -1.2 percent in the latest sub-period. China also began to be crowded out in the metals sector $(-0.1$ and -0.1 percent, respectively).In footwear and miscellaneous it was not until the latest subperiod that China began to be crowded out by rivals (by -0.2 and -0.3 percent, respectively). For machines and electronics, China still crowd out rivals but to a reduced extent.

Table 9. Distribution of China's Crowding-out Effect by Industry in Medium Segment

\begin{tabular}{llllll}
\hline & $(1)$ & $(2)$ & $(3)$ & $(4)$ & $(5)$ \\
Manufacturing sectors & $1996-$ & $1996-$ & $2002-$ & $2007-$ & $2012-$ \\
& 2016 & 2001 & 2006 & 2011 & 2016 \\
\hline Chemicals(28-38) & 0.8 & 0.4 & 0.4 & 0.0 & 0.0 \\
Plastic or rubber(39-40) & 0.3 & 0.0 & 0.2 & 0.1 & 0.1 \\
Hides and skins (41-43) & 0.1 & 0.1 & 0.0 & 0.0 & 0.0 \\
Wood (44-49) & 1.0 & 0.7 & 0.2 & 0.0 & 0.1 \\
Textiles and clothing(50-63) & -1.3 & -0.2 & 0.4 & -0.3 & -1.2 \\
Footwear(64-67) & -0.1 & 0.0 & 0.0 & 0.0 & -0.2 \\
Stone and glass(68-71) & -0.3 & -0.4 & 0.1 & 0.1 & 0.0 \\
Metals (72-73) & 0.6 & 0.4 & 0.5 & -0.1 & -0.1 \\
Machines and electronics(84- & 6.9 & 2.0 & 3.1 & 1.3 & 0.6 \\
85) & & & & & \\
Transport equipment(86-89) & 0.5 & 0.0 & 0.3 & 0.2 & 0.0 \\
Miscellaneous(90-96) & 0.2 & 0.1 & 0.4 & 0.1 & -0.3 \\
Total & 8.9 & 3.0 & 5.5 & 1.4 & -1.1 \\
\hline SourC: Authors' own & & & & & \\
\hline
\end{tabular}

Source: Authors’ own calculation.

\section{(3) High-quality Segment}

In the high-quality segment, China's 0.2-percent overall crowding-out effect comes from all sectors apart from machines and electronics and miscellaneous between 1996 and 2016. For the first three sub-periods, China crowds out rivals to a minor degree in all sectors apart from miscellaneous ( -0.1 percent) in the first sub-period and 
stone and glass sector $(-0.1$ percent) in the third sub-period. In the most recent subperiod, the overall crowding-out effect became a crowded-out effect as in the lowquality and medium-quality segments. China was crowded out most in machines and electronics ( 0.9 percent), followed by the miscellaneous ( -0.3 percent) and stone and glass sectors ( -0.1 percent). In all other sectors, China maintained a weak crowdingout effect.

Table 10. Distribution of China’s Crowding-out Effect by Industry in High Segment (\%)

\begin{tabular}{llllll} 
Manufacturing & $(1)$ & $(2)$ & $(3)$ & $(4)$ & $(5)$ \\
& $1996-2016$ & $1996-2001$ & $2002-2006$ & $2007-2011$ & $2012-2016$ \\
Chemicals(28-38) & 0.2 & 0.0 & 0.2 & 0.0 & 0.0 \\
Plastic or rubber(39-40) & 0.2 & 0.0 & 0.0 & 0.0 & 0.1 \\
Hides and skins (41-43) & 0.0 & 0.0 & 0.0 & 0.0 & 0.0 \\
wood (44-49) & 0.0 & 0.0 & 0.0 & 0.0 & 0.0 \\
textiles and clothing(50-63) & 0.1 & 0.0 & 0.0 & 0.0 & 0.0 \\
Footwear(64-67) & 0.0 & 0.0 & 0.0 & 0.0 & 0.0 \\
Stone and glass(68-71) & 0.0 & 0.0 & 0.1 & -0.1 & -0.1 \\
Metals (72-73) & 0.1 & 0.0 & 0.0 & 0.0 & 0.0 \\
Machines and electronics(84-85) & -0.1 & 0.1 & 0.2 & 0.4 & -0.9 \\
Transport equipment(86-89) & 0.2 & 0.0 & 0.0 & 0.0 & 0.1 \\
Miscellaneous(90-96) & -0.2 & -0.1 & 0.1 & 0.1 & -0.3 \\
Total & 0.2 & 0.2 & 0.7 & 0.6 & -1.2 \\
\hline
\end{tabular}

Source: Authors’ own calculation.

Relative to lower quality segments, in high-quality segments China’s crowdingout or crowded-out effect is negligible in size. This demonstrates the weak competitiveness change of China's exports in the high quality segment. China recently appears to have made minor progress in transport equipment and plastic or rubber. In addition, China gained a negligible share in textiles and clothing, although it lost market share in the medium and low-quality segments of this sector. China also recently lost competitiveness in machines and electronics. 


\section{Discussion}

The above results suggest that although there has been a massive relocation of manufacturing production from developed countries to China and other developing countries, the relocation is mainly in lower quality product segments. Therefore, although China has emerged as a global manufacturing powerhouse (McKay and Song, 2010)and accounts for nearly half of the lower quality products in the Japanese manufactured goods import market, China is still relatively weak with respect to highquality products. Between 1996 and 2016, China’s crowding-out effect in high-quality segments is a negligible 0.2 percent, but in low and medium-quality segments the effect is 14and 8.9 percent respectively. In addition, the club for suppliers of the high-quality product is stable: developed countries have a relatively constant market share. This indicates that moving up in the export quality ladder is slow and difficult.

With its economic development proceeding, China is now facing a crowded-out effect in all quality segments. Low-quality product exporters are facing difficulty covering rising labor costs because of low profit margins. Since mid-2007, some Chinese manufacturers, in particular those in labor-intensive and highly polluting industries, have faced pressure to either shut down or relocate due to a number of factors, including unfavorable central government policies, a stronger yuan, increasing costs of energy and raw materials, strengthening environmental regulations and increased labor protections, such as the introduction of a minimum wage (Sharif and Huang, 2012).Therefore, it was in the low segment that the relatively large shift from a crowding-out effect to a crowded-out effect was first observed during the sub-period of 
2007-2011, mostly with respect to ASEAN competitors in Japan’s market. This was then followed by a similar shift in more sectors. For instance, between 2012 and 2016, China was crowded out most in the medium-quality textile and clothing sector and highquality machines and electronics sector, mostly with respect to ASEAN countries. As the labor cost and other costs have continued to rise, if competitiveness cannot outpace growing costs, the crowded-out effect would emerge in more sectors and at a larger scale.

The Chinese Government has responded to these challenges by initiating policies to assist in moving up the export ladder: China’s launch of “Manufacturing 2025” will help to advance it from the lower quality segment to the higher quality one and its Belt and Road Initiative will facilitate the relocation of low segment industries to other countries (Vangeli, 2017).

Historically, the loss of market share in the low segment may not be a negative development for more developed countries because those losses arise from low valueadded and labor-intensive industries that more developed countries usually do not have comparative advantage. In contrast, they can gain welfare by focusing on high valueadded products, the market share of which has not been challenged. Such a win-win outcome can be explained by the flying geese model, which was originally proposed by Akamatsu(1962)to explain Japan’s upgrade of its manufacturing industries, ${ }^{2}$ which resulted in the relocation of lower value-added industries to other countries, creating

\footnotetext{
${ }^{2}$ Japan's manufacturing industries have moved from labor-intensive industries, such as textiles, to a second tier of heavy capital-intensive industries, such as steel and shipbuilding, to a third tier of assembly-oriented industries, such as motor vehicles, electronics and machine tools, to a fourth tier of high technology industries, such as biotechnology and super-conductors.
} 
new leading geese(Lloyd, 1996). Using data from the textile and apparel industry from 1998 to 2011, Ruan and Zhang (2014) show the existence of the "flying geese” pattern of industrial relocation within China. Our empirical analysis complements their finding by providing new evidence that the labor-intensive textiles and clothing sector in both low-quality and medium-quality segments has been increasingly relocated out of China due to rising labor costs. In addition, machines and electronics in the low-quality segment, where most of the business in China is in the form of processing trade that belongs to the labor-intensive assembly part of the value chain, has experienced similar relocation out of China at a greater pace than for low-quality textile and clothing sector. Looking ahead, such a crowded-out effect could also be beneficial for both China and the recipient countries due to their different comparative advantages. Relocation of industries is a natural result of international development. By accepting even this lowquality segment manufacturing, less developed countries can be integrated into the global supply chain, develop their comparative advantage and build up economic and other capacity. Our findings demonstrate that less developed countries in ASEAN, that is, Cambodia, Myanmar and Vietnam, are gaining market share. This fact is in line with ASEAN's top priority to narrow the development gap with the six older ASEAN member states and Cambodia, Lao, Myanmar and Vietnam(The ASEAN Secretariat, 2016). Further relocation of low-quality manufacturing from China to other developing countries, such as Cambodia and Vietnam, will further advance the level of industrialization in these countries, in addition to environmental benefits that have recently been demonstrated(Han et al., 2018).

\section{Conclusion}

Product quality is an important dimension in the recent theoretical and empirical international trade research. By employing the most detailed HS nine-digit productlevel data and the recent extension of CMS methodology, this paper has provided evidence of crowding-out and crowded-out effects across different product quality 
segments and across manufacturing sectors, which complements the previous related literature. We also undertook a supplementary analysis of China's crowding(ed) out effect across manufacturing sectors by quality segments.

The results show that a crowding-out effect exists for China's exports in all quality segments in almost all sectors between 1996 and 2006. However, during the sub-period of 2007-2011, this crowding-out effect became a crowded-out effect in the low-quality segment in the textile and clothing sector and wood sector, especially with respect to ASEAN countries. This displacement of China's exports coincided with when it became an upper-middle-income country. The shift from crowding-out to crowded-out also occurred in the medium-quality and high-quality segments in the most recent subperiod in more sectors between 2012 and 2016. The present paper observes that industrial relocation is a natural phenomenon in international development. However, initially most of the relocation occurred in the low-quality segment.

Based on this discussion, the following policy implications can be drawn. The findings suggest that rather than being an exception, China is following the well-known “flying geese” pattern of development previously traveled by other East Asian economies. The crowded-out effect is in line with the industrial relocation that is behind the "East Asian Miracle” and, thus, could achieve win-win outcomes for countries involved. China has previously been a beneficiary of export orientation and industrial relocation and now lower income countries are also benefiting as China itself becomes a driver of the next wave of industrial relocation.

Lower-income developing economies such as those in ASEAN would do well to 
be open to receive those relocated low value-added industries for their own benefit in promoting economic and capacity development through participation in the international supply chain. While it may be low value-added, less technologically advanced and labor-intensive, specialization in the production and export of low-quality products could provide the impetus to transform from an agricultural to an industrial economy. In contrast, less developed countries should not rush to leapfrog up the export ladder as even China, after decades of development, is only starting to move from the low-quality segment to the medium-quality segment. ASEAN countries should welcome international relocation to their less developed members as a way to promote the narrowing development gap to which ASEAN aspires.

However, climbing up the product quality ladder takes time, and, thus, the relocation policy in China is best implemented gradually. Although China needs to climb the export ladder due to rising labor costs, its policy of industrial relocation should not be too radical or sudden. The stability in high segments indicates that it is not an easy task to break through. Considering the rising labor costs, foreign direct investment outflows and the resulting industrial reallocation across ASEAN countries, especially the lower income developing members, it is likely that China will see losses in the low-quality segment continue.

\section{References}

Akamatsu, K., 1962, “A historical pattern of economic growth in developing Countries,” The Developing Economies, Vol. 1, pp. 3-25.

Anh-Dao, T. T., 2010, "Vietnam's export performance in the face of China's competitive challenge," Comparative Economic Studies, Vol. 52 No. 3, pp. 40527. 
Baak, S., 2014, "Do Chinese and Korean products compete in the Japanese market? An investigation of machinery exports," Journal of the Japanese and International Economies, Vol. 34, pp. 256-71.

Batista, J. C., 2008, “Competition between Brazil and other exporting countries in the US import market: A new extension of constant-market-shares analysis,” Applied Economics, Vol. 40, No. 19, pp. 2477-87.

Batista, J. C. and Y. Liu, 2017, "Export quality and the dynamics of North-South competition,” World Economy, Vol. 40, No. 1, pp. 207-32.

CEIC, 2017, "CEIC database” [online; cited 16 August 2017]. Available from: https://www.ceicdata.com/en.

Cheptea, A., L. Fontagnéand S. Zignago, 2014, "European export performance," Review of World Economics, Vol. 150, No. 1, pp. 25-58.

Du, Y. and Y. Lu, 2018, "The Great Opening up and the Roadmap for the Future: The Story of China’s International Trade”, China \& World Economy, Vol. 26 No.2, pp 68-93.

Eichengreen, B., Y. Rhee and H. Tong, 2007, "China and the exports of other Asian countries,” Review of World Economics, Vol. 143, No. 2, pp. 201-26.

Fagerberg, J. and G. Sollie, 1987, "The method of constant market shares analysis reconsidered,” Applied Economics, Vol. 19, No. 12, pp. 1571-83.

Fontagné, L., G. Gaulier and S. Zignago, 2008, "Specialization across varieties and North-South competition,”Economic Policy, Vol. 23, pp. 51-91.

Greenaway, D., A. Mahabir and C. Milner, 2008, "Has China displaced other Asian countries’ exports?” China Economic Review, Vol. 19, No. 2, pp. 152-69.

Holst, D. R. and J. Weiss, 2004, “ASEAN and China: Export rivals or partners in regional growth?” World Economy, Vol. 27, No. 8, pp. 1255-74.

Han, L., Han, B., Shi, X., Su, B., Lv, X., Lei, X., 2018. Energy efficiency convergence across countries in the context of China's Belt and Road initiative. Applied Energy, Vol. 213, pp112-122.

Lin, Y., 2015, “Is China Relinquishing Manufacturing Competitiveness to Mexico in US Markets?”, China and World Economy, Vol. 23 No. 4, pp. 104-124.

Lloyd, P. J., 1996, "The role of foreign investment in the success of Asian industrialization,”Journal of Asian Economics, Vol. 7, No. 3, pp. 407-33.

McKay, H. and L. Song, 2010, "China as a Global Manufacturing Powerhouse: Strategic Considerations and Structural Adjustment”, China \& World Economy, Vol. 18 No. 1, pp. 1-32.

Schott, P. K., 2004, “Across-product versus within-product specialization in international trade,” The Quarterly Journal of Economics, Vol. 119, No. 2, pp. 647-78.

Sharif, N. and C. Huang, 2012, "Innovation strategy, firm survival and relocation: The case of Hong Kong-owned manufacturing in Guangdong Province, China,” Research Policy, Vol. 41, No. 1, pp. 69-78.

The ASEAN Secretariat, 2016, "Initiative for ASEAN integration (IAI) work plan III," [online; cited 26 October 2017]. Available from: 
http://asean.org/storage/2016/09/09rev2Content-IAI-Work-Plan-III.pdf.

Tyszynski, H., 1951, "World Trade in Manufactured Commodities, 1899 - 1950," Manchester School, Vol. 19, No. 3, pp. 272-304.

Vangeli, A., 2017, “China's Engagement with the Sixteen Countries of Central, East and Southeast Europe under the Belt and Road Initiative", China and World Economy, Vol. 25 No. 5, pp. 101-124.

World Trade Organisation, 2017, “World Trade Statistical Review 2017” [online; cited 26 October 2017]. Available from: https://www.wto.org/english/res_e/statis_e/wts2017_e/wts17_toc_e.htm. 